\title{
Selective protein adsorption for implantable biomaterials: A new road to bioactivity
}

\author{
Carlo Galli* and Stefano Guizzardi \\ Department of Medicine and Surgery, University of Parma, Italy
}

Most regenerative strategies rely on the use of tissue substitutes, which act as scaffolds to stabilize the blood clot and promote and support the organization of a provisional matrix that will eventually allow the ingrowth of progenitors cells from neighbouring tissues and the deposition of novel tissue [1-4]. To achieve this ambitious goal biomaterials must provide a favourable microenvironment that is conductive to cell attachment, proliferation and to the expression of an adequate cell phenotype for the formation of the desired tissue. Unlike natural tissues, exogenous biomaterials do not possess the structural complexity of extracellular matrix to provide articulated biological signals, however, upon their implantation into a receiving structure, they do get in contact with blood and get enriched for proteins, which in turn represent a first acquired biological layer capable to mediate between the material and cells [5]. Strategies aiming at guiding the selective adsorption of clinically useful proteins on biomaterials are therefore much sought after. A viable approach that has long been pursued in the creation of implantable scaffolds was the enrichment of biomaterials and devices with bioactive molecules or fragments thereof, such as adhesive peptides or proteins, e.g. fibronectin, fibrinogen or vitronectin [6-9]. However, this approach is limited by the need to bind molecules with often exceedingly large molecular weight and limited stability and bioavailability and possibly by regulatory hurdles, as the addition of bioactive molecules such as growth factors to a medical device can pose questions as to their regulatory status. An alternative approach for the selective enrichment of biomaterials is however the addition of selective docking mechanisms on the device surface. The underlying idea is that these docking points can capture relevant molecules from the surrounding microenvironment and retain them on the biomaterial. One possible advantage is that smaller and more robust molecules can be used to capture and retain large proteins. Moreover, target molecules are autogenous and no compatibility issues may ensue. Furthermore, these docking points are structural elements without pharmacological activity and cannot be considered drugs for regulatory purposes. Several alternative approaches have been proposed to achieve this goal [10]. Components of the extracellular matrix, e.g. glycosaminoglycans or heparan sulfate, are known to retain growth factors and bioactive molecules such as PDGF or TGF $\beta$ by interacting with specific domains $[11,12]$. Biomaterials have been then grafted with such components to promote pre-implant loading [13] or partially selective enrichment of the scaffold with bioactive molecules [14]. Alternatively, streptavidin-biotin systems have been proposed to support selective enrichment for target molecules [15], although this approach is suitable only for pre-implant scaffold loading, as target bioactive molecules require biotynilation prior to loading. A different strategy was proposed by Freire [16,17] by immobilizing anti BMP2 antibodies on biomaterials, to promote selective binding of growth factors on scaffolds. The use of antibodies may however be limited by the size of these proteins, by compatibility issues, by constraints in the production of antibodies. To bypass these issues, aptamers were then proposed. One such approach was reported by Galli, et al. [18] and Parisi, et al. [19]. In these papers, anti-Fibronectin aptamers were used as docking points on hyaluronic acid-polyethylenglycole hydrogels and chitosan hydrogels respectively. This concept was pioneered by Hoffman, et al. [20], who used aptamers to sort cells out the blood flow using dyalisis membranes. Clearly Hoffman had a different aim, i.e. to remove cells from blood for analysis or therapy purposes, using an ex vivo approach, but this study highlighted the great potential of aptamers for similar purposes. Aptamers are small molecules, often oligonucleotides that can specifically bind to target molecules thanks to their secondary structure. Although peptide or RNA aptamers [21] do exist, most aptamers are either double or single-stranded DNA molecules, such as in the papers mentioned above. The authors showed that addition of aptamers against Fibronectin to hyaluronic acid- polyethylenglycole (PEG) hydrogels, a substrate that offers scant attachment to cells, improved cell retention and cell migration inside the hydrogel, as Fibronectin is a molecule that possesses integrin-binding domains. Interestingly, aptamers against Fibronectin improved cell adhesion on chitosan as well. Chitosan is a derivative of chitin, a structural polysaccharide commonly found in crustaceans, insects and fungi [22]. Chitosan is capable to establish a wide range of weak bonds with several molecules and adsorbs a great amount of proteins when in contact with plasma [23]. The authors have also shown that chitosan did abundantly bind Fibronectin from plasma in the absence of aptamers, however attachment of murine osteoblastic MC3T3 cells was impaired. Addition of aptamers did not increase the amount of adsorbed Fibronectin, leaving open the possibility that aptamers would actually improve the bioavailability of this molecule by preserving a more functional conformation, possibly avoiding its loss of 3D shape due to aspecific interactions with chitosan. Aptamers would therefore create beacons of functional Fibronectin, which would then serve as nucleation points for further molecule autoassembly, and subsequent cell attachment. This approach has clearly still a lot of potential to be explored, especially if aptamers against different molecules are to be employed, e.g. against growth factors that are commonly found in wounds. Zhang et al have independently proposed gelatin-PEG hydrogels containing anti VEGF aptamers, capable to improve attachment of HUVEC cells [24]. Platelet derived Growth Factor is another interesting option, as it is released in great amounts from platelets when these get activated during clot formation.

Correspondence to: Carlo Galli, Department of Medicine and Surgery, University of Parma, Italy, E-mail: carlo.galli1@unipr.it

Received: August 06, 2017; Accepted: August 22, 2017; Published: August 24, 2017 
Biomaterials could then capture it from the plasma and get imbued with this mitogen growth factor, thus attracting mesenchymal progenitors into the scaffold, and harnessing the resources of the organism, without resorting to providing recombinant or otherwise exogenous replacement compounds. Polystyrene scaffolds enriched with aptamers against PDGF as drug delivery systems for sustained release of growth factors into wounds have been reported [25], although data on such scaffolds capable to capture endogenous PDGF in wounds to promote scaffold colonization are still missing.

We therefore appear to be at the eve of promising developments for scaffold engineering, whereby structures can be created that recruit endogenous components, to maximize biomimetics and eventually ameliorate the clinical results of therapies.

\section{References}

1. Wen Y, Xun S, Haoye M, Baichuan S, Peng C, et al. (2017) 3D printed porous ceramic scaffolds for bone tissue engineering: a review. Biomater Sci. [Crossref]

2. Mondschein RJ, Kanitkar A, Williams CB, Verbridge SS, Long TE (2017) Polymer structure-property requirements for stereolithographic 3D printing of soft tissue engineering scaffolds. Biomaterials 140: 170-188. [Crossref]

3. Chaudhuri R, Ramachandran M, Moharil P, Harumalani M, Jaiswal AK (2017) Biomaterials and cells for cardiac tissue engineering: Current choices. Mater Sci Eng C Mater Biol Appl 79: 950-957. [Crossref]

4. Mata A, Azevedo HS, Botto L, Gavara N, Su L (2017) New Bioengineering Breakthroughs and Enabling Tools in Regenerative Medicine. Curr Stem Cell Rep 3: 83-97. [Crossref]

5. Cross MC, Toomey RG, Gallant ND (2016) Protein-surface interactions on stimuliresponsive polymeric biomaterials. Biomed Mater 11:022002.

6. Pereira AM, Machado R, da Costa A, Ribeiro A, Collins T, et al. (2017) Silk-based biomaterials functionalized with fibronectin type II promotes cell adhesion. Acta Biomater 47: 50-59. [Crossref]

7. Cacchioli A, Ravanetti F, Bagno A, Dettin M, Gabbi C (2009) Human vitronectinderived peptide covalently grafted onto titanium surface improves osteogenic activity: A pilot in vivo study on rabbits. Tissue Eng Part A 15: 2917-2926. [Crossref]

8. Marcinczyk M, Elmashhady H, Talovic M, Dunn A, Bugis F, et al. (2017) Laminin-111 enriched fibrin hydrogels for skeletal muscle regeneration. Biomaterials 141: 233-242. [Crossref]

9. Galli C, Parisi L, Elviri L, Bianchera A, Smerieri A, et al. (2016) Chitosan scaffold modified with D-(+) raffinose and enriched with thiol-modified gelatin for improved osteoblast adhesion. Biomed Mater 11: 015004. [Crossref]

10. Guan X, Avci-Adali M, Alarçin E, Cheng H, Kashaf SS, et al. (2017) Development of hydrogels for regenerative engineering. Biotechnol $J 12$.
11. Rolny C, Spillmann D, Lindahl U, Claesson-Welsh L (2002) Heparin amplifies plateletderived growth factor (PDGF)-BB-induced PDGF alpha-receptor but not PDGF betareceptor tyrosine phosphorylation in heparan sulfate-deficient cells. Effects on signal transduction and biological responses. J Biol Chem 277: 19315-19321. [Crossref]

12. Rider CC (2006) Heparin/heparan sulphate binding in the TGF-beta cytokine superfamily. Biochem Soc Trans 34: 458-460. [Crossref]

13. Tae G, Scatena M, Stayton PS, Hoffman AS (2006) PEG-cross-linked heparin is an affinity hydrogel for sustained release of vascular endothelial growth factor. J Biomater Sci Polym Ed 17: 187-197. [Crossref]

14. Guan S, Zhang XL, Lin XM, Liu TQ, Ma XH, Cui ZF (2013) Chitosan/gelatin porous scaffolds containing hyaluronic acid and heparan sulfate for neural tissue engineering. J Biomater Sci Polym Ed 24: 999-1014. [Crossref]

15. Wylie RG, Ahsan S, Aizawa Y, Maxwell KL, Morshead CM, et al. (2011) Spatially controlled simultaneous patterning of multiple growth factors in three-dimensional hydrogels. Nat Mater 10: 799-806. [Crossref]

16. Freire MO, You HK, Kook JK, Choi JH, Zadeh HH (2011) Antibody-mediated osseous regeneration: a novel strategy for bioengineering bone by immobilized anti-bone morphogenetic protein-2 antibodies. Tissue Eng Part A 17: 2911-2918. [Crossref]

17. Ansari S, Moshaverinia A, Pi SH, Han A, Abdelhamid AI, et al. (2013) Functionalization of scaffolds with chimeric anti-BMP-2 monoclonal antibodies for osseous regeneration. Biomaterials 34: 10191-10198. [Crossref]

18. Galli C, Parisi L, Piergianni M, Smerieri A, Passeri G, et al. (2016) Improved scaffold biocompatibility through anti-Fibronectin aptamer functionalization. Acta Biomater 42: 147-156.

19. Parisi L, Galli C, Bianchera A, Lagonegro P, Elviri L, et al. (2017) Anti-fibronectin aptamers improve the colonization of chitosan films modified with D-(+) Raffinose by murine osteoblastic cells. J Mater Sci Mater Med 28: 136. [Crossref]

20. Hoffmann J, Paul A, Harwardt M, Groll J, Reeswinkel T, et al. (2008) Immobilized DNA aptamers used as potent attractors for porcine endothelial precursor cells. $J$ Biomed Mater Res A 84: 614-621.

21. Hoffmann S, Hoos J, Klussmann S, Vonhoff S (2011) RNA aptamers and spiegelmers: synthesis, purification, and post-synthetic PEG conjugation. Curr Protoc Nucleic Acid Chem Chapter 4: Unit 4. [Crossref]

22. Sivashankari PR, Prabaharan M2 (2016) Prospects of chitosan-based scaffolds for growth factor release in tissue engineering. Int J Biol Macromol 93: 1382-1389. [Crossref]

23. Bianchera A, Salomi E, Pezzanera M, Ruwet E, Bettini R, Elviri L (2014) Chitosan hydrogels for chondroitin sulphate controlled release: an analytical characterization. $J$ Anal Methods Chem 2014: 808703.

24. Zhang YS, Yue K, Aleman J, Moghaddam KM, Bakht SM, et al. (2017) 3D bioprinting for tissue and organ fabrication. Ann Biomed Eng 45: 148-163. [Crossref]

25. Soontornworajit B, Zhou J, Shaw MT, Fan TH, Wang Y (2010) Hydrogel functionalization with DNA aptamers for sustained PDGF-BB release. Chem Commun (Camb) 46: 1857-1859. [Crossref]

Copyright: (C2017 Galli C. This is an open-access article distributed under the terms of the Creative Commons Attribution License, which permits unrestricted use, distribution, and reproduction in any medium, provided the original author and source are credited. 